\title{
Properties and localization of DNA methyltransferase in preimplantation mouse embryos: implications for genomic imprinting
}

\author{
Linda L. Carlson, Andrea W. Page, ${ }^{1}$ and Timothy H. Bestor ${ }^{2}$ \\ Laboratory of Human Reproduction and Reproductive Biology, Department of Anatomy and Cellular Biology, Harvard
} Medical School, Boston Massachusetts 02115 USA

Preimplantation mouse embryos contain very high levels of DNA methyltransferase activity. We show here that the form of DNA methyltransferase (DNA MTase) in early embryos differs from the form found in other cells and tissues by a slightly higher mobility on gel electrophoresis. Levels of DNA MTase were found to be very high throughout preimplantation development even though levels of 5 -methylcytosine $\left(\mathrm{m}^{5} \mathrm{C}\right)$ in nuclear DNA are known to undergo a substantial decline in the same period. Confocal laser scanning microscopy of mouse embryos stained with DNA MTase-specific antibodies showed striking developmentally regulated changes in the distribution of DNA MTase. From the oocyte stage to the four-cell-stage, most DNA MTase was concentrated in peripheral cytoplasm, and nuclei did not contain detectable DNA MTase. In four- and eight-cell embryos, DNA MTase was seen in cytoplasmic granules; and in eight-cell embryos, DNA MTase was also present in large amounts in nuclei. Nuclei of blastocysts stained only faintly, whereas the cytoplasmic granules remained prominent. Paradoxically, DNA MTase was found to be at its highest levels in nuclei at a developmental stage where levels of $\mathrm{m}^{5} \mathrm{C}$ in DNA are decreasing most rapidly. Changes in methylation patterns in preimplantation embryos are therefore proposed to be under the control of unidentified regulatory factors rather than DNA MTase itself; these regulatory factors could be members of the group that contains the products of the Ssm-1 and Imp-1 genes, which are involved in the regulation of genomic imprinting.

[Key Words: DNA methyltransferase; preimplantation mouse embryos; genomic imprinting]

Received September 8, 1992; revised version accepted October 19, 1992.

Methylation patterns established in the sperm and oocyte genomes during gametogenesis undergo sweeping changes during preimplantation development (Monk et al. 1987; Monk 1990). The DNAs of both maternal and paternal genomes show a net loss of 5-methylcytosine $\left(\mathrm{m}^{5} \mathrm{C}\right)$ between the eight-cell and blastocyst stages, with the paternal genome being most affected (Monk 1990; Chaillet et al. 1991). The DNA of blastocysts has been reported to have the lowest levels of $\mathrm{m}^{5} \mathrm{C}$ of any tissue or developmental stage, with the possible exception of DNA of primordial germ cells (Monk et al. 1987; Monk 1990; Chaillet et al. 1991). Although measurements of net $\mathrm{m}^{5} \mathrm{C}$ levels reflect the average methylation status of $5 \times 10^{7}$ individual $\mathrm{CpG}$ sites per genome, studies of an imprinted transgene (Chaillet et al. 1991) and specific endogenous genes (Takri et al. 1992) suggest that the behavior of individual sequences during preimplantation

\footnotetext{
${ }^{1}$ Present address: Department of Biology, Massachusetts Institute of Technology, Cambridge Massachusetts 02139 USA.

${ }^{2}$ Corresponding author.
}

development may be similar to that of the genome-wide average. Levels of $\mathrm{m}^{5} \mathrm{C}$ increase after implantation, and adult levels are reached around the time of gastrulation (Monk 1990). Despite the reorganization of methylation patterns during early development, the maternal and paternal genomes retain distinct differences in methylation patterns that are thought to be involved in genomic imprinting (Chaillet et al. 1991).

Perturbations of methylation patterns are incompatible with normal mammalian development, as shown by recent gene-targeting experiments in which mutations of the DNA (cytosine-5)-methyltransferase (DNA MTase) gene caused developmental abnormalities and lethality in mutant mouse embryos but had no effect on the proliferation of mutant embryonic stem cells (Li et al. 1992).

A single form of DNA MTase has been identified to date in mammals (Bestor et al. 1988). This enzyme comprises an amino-terminal domain of 1000 amino acids that contains a novel zinc DNA-binding site linked to a carboxy-terminal domain of 500 amino acids that is closely related to a class of bacterial restriction methyl- 
transferases. Cleavage of protease-sensitive sites between the amino- and carboxy-terminal domains eliminates the preference of the enzyme for hemimethylated DNA, suggesting that the amino-terminal domain is an inhibitor of de novo methylation (Bestor 1992). The intrinsic sequence specificity of the form of DNA MTase purified from somatic cells is limited to the CpG dinucleotide and cannot account for the formation of sequence-specific methylation patterns, especially as cell types with different methylation patterns contain indistinguishable forms of DNA MTase (Bestor et al 1988). However, the primary function of DNA MTase in differentiated somatic cells is the clonal propagation of stable methylation patterns.

It has been suggested that the DNA methylating system of early embryos, where methylation patterns are dynamic, might differ significantly from that of somatic cells (Holliday and Pugh 1975; Riggs 1975; Jähner and Jaenisch 1984; for review, see Razin and Cedar 1991). This report describes the characteristics of DNA MTase in preimplantation embryos and compares the embryonic and somatic enzymes. In agreement with previous results (Howlett and Reik 1991; Monk et al. 1991), DNA MTase was found to be present at very high levels in oocytes; and although the amount per embryo was found to decrease by a factor of approximately four by the blastocyst stage, DNA MTase levels remained very high relative to somatic cells throughout preimplantation development. The enzymatic properties of embryonic DNA MTase were not distinguishable from those of the somatic form, and confocal laser scanning microscopy of embryos stained with DNA MTase-specific antibodies showed striking developmentally regulated changes in localization of DNA MTase. However, neither the enzymatic characteristics nor cellular localization of DNA MTase could be directly related to the changes in methylation patterns undergone by the DNA of preimplantation embryos, and we suggest that additional regulatory factors must be involved.

\section{Results}

Quantitation of DNA MTase in preimplantation mouse embryos

Immunoblot analysis with polyclonal antibodies to DNA MTase (Fig. 1) showed that levels of DNA MTase are $\sim 3000$-fold higher in oocytes and one-cell embryos than in murine erythroleukemia (MEL) cells when compared on a per nucleus basis. Densitometric analysis of immunoblots showed that DNA MTase levels in whole embryos declined somewhat during early development; eight-cell embryos had half the enzyme content of oocytes and one-cell embryos, and blastocysts had about one-fourth the amount (Fig. 1). However, DNA MTase levels remained very high in the blastocyst relative to somatic cells. It was calculated that the DNA MTase content on a per nucleus basis of cells of the blastocyst at the 100-cell stage was eight times greater than in MEL cells. MEL cells provide a conservative standard of com-

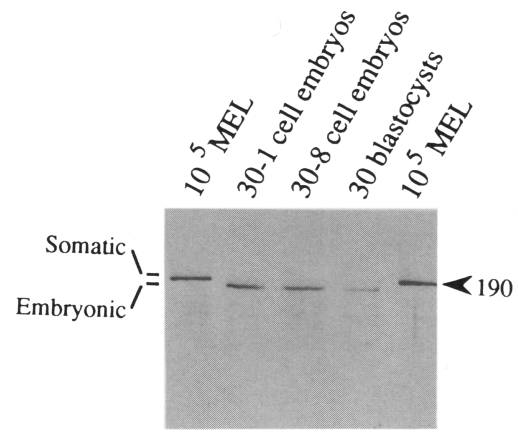

Figure 1. Immunoblot analysis of DNA MTase in early mouse embryos. Whole-cell lysates from 30 preimplantation embryos of the specified stages (lanes 2-4) and lysates of $10^{5} \mathrm{MEL}$ cells were separated on SDS $-6 \%$ polyacrylamide gels and transferred to nitrocellulose sheets. The blots were probed with antipATH52 and alkaline phosphatase-conjugated goat anti-rabbit IgG. Oocytes can be seen to contain large amounts of DNA MTase, which was found by densitometry to decline by a factor of 2 at the eight-cell stage and a factor of 4 at the blastocyst stage.

parison, as they have amplified the DNA MTase gene and express high levels of DNA MTase (Bestor et al. 1988). When compared with mouse 3T3 fibroblasts, oocytes and blastocysts were calculated to have 15,000 fold and 40-fold more DNA MTase per nucleus, respectively. These results show that DNA MTase levels are very high throughout preimplantation development.

\section{Altered electrophoretic mobility of embryonic DNA MTase}

DNA MTase from embryos migrates through SDS-6\% polyacrylamide gels with a slightly higher mobility than the enzyme from MEL cells (Fig. 1), whereas DNA MTase from all mouse cell lines examined comigrates with MEL cell DNA MTase (data not shown). As shown in Figure 2, expression of the full-length MEL cell DNA MTase cDNA in COS cells or by in vitro transcriptiontranslation produced a protein that comigrated with the embryonic, rather than the somatic, form. This suggests that the increased mobility of DNA MTase from oocytes and embryos is caused by alternative translation start sites or the lack of post-translational modification. Many types of post-translational modification do not occur in proteins synthesized by in vitro translation in reticulocyte lysates, and the murine enzyme may not be processed properly in COS cells or may be produced in amounts that saturate modification systems. The nature of the presumed modification that retards the migration of the somatic form of DNA MTase is not known.

\section{Substrate and de novo sequence specificity of embryo DNA MTase}

The somatic form of DNA MTase prefers hemimethylated DNA (Gruenbaum et al. 1982; Bestor and Ingram 1983) and poly[d(I-C)]/poly[d(I-C)] (Pedrali-Noy and 




Figure 2. Evidence that the difference in electrophoretic mobility between embryonic and somatic DNA MTase is the result of post-translational modification. (COS) Lysate of COS1 cells transfected with the expression construct pEMT, which contains the cDNA for DNA MTase from MEL cells (Czank et al. 1991). (MEL) Whole-cell lysate of $10^{5} \mathrm{MEL}$ cells. (Oocytes) Whole-cell lysate of 20 embryos. (MEL + COS) A mixture of a lysate of $10^{5} \mathrm{MEL}$ cells and extract from COS1 cells transfected with pEMT. (IVT) DNA MTase made from a cDNA from MEL cells by in vitro translation with $\mathrm{T} 3$ polymerase and translation in a reticulocyte lysate. (IVT-RNA) In vitro translation in the absence of added RNA. DNA MTase from oocytes can be seen to migrate with the somatic form of DNA MTase only when the somatic form is produced by in vitro transcription-translation or expression in COS1 cells.

Weissbach 1986) as substrates. To determine whether this was also true of DNA MTase from embryos, lysates were prepared from unfertilized oocytes and eight-cell preimplantation embryos, and the initial velocity of transmethylation of these lysates was tested with poly[d(I-C)]/poly[d(I-C)], unmethylated Escherichia coli DNA, and hemimethylated E. coli DNA as substrates (Fig. 3). Both preparations showed a clear preference for hemimethylated DNA and poly[d $(\mathrm{I}-\mathrm{C})] /$ poly $[\mathrm{d}(\mathrm{I}-\mathrm{C})]$ over unmethylated DNA, as does the somatic form of DNA MTase. The de novo sequence specificities of the embryonic and MEL cellular DNA MTase were compared as described (Bestor and Ingram 1985; Bestor 1987), and no significant differences were observed (L.L. Carlson and T. Bestor, unpubl.). DNA MTase from mammalian cells has been shown to recognize primarily the sequence 5 'CG-3' (Gruenbaum et al. 1982; Bestor and Ingram 1983; Hubrich-Kuhner et al. 1989).

\section{Localization of DNA MTase during preimplantation development}

The distribution of DNA MTase within preimplantation mouse embryos was determined by staining fixed embryos with anti-DNA MTase antibodies and examination in the confocal laser scanning microscope. The antibodies were highly specific, as established by the immunoblot shown in Figure 1 and by the observation of greatly reduced staining in mouse ES cells homozygous for a partial loss-of-function mutation in the DNA MTase gene ( $\mathrm{Li}$ et al. 1992; L. Carlson, E. Li, and T. Bestor, unpubl.). The intracellular distribution of DNA MTase went through striking changes during preimplantation development; as shown in Figure 4, the nuclei of one- and two-cell embryos were devoid of appreciable staining, whereas the cytoplasm near the plasma membrane stained intensely (Fig. 4A-D). At the four-cell stage, some staining was observed in the nucleus, near the plasma membrane, and in small aggregates throughout the cytoplasm (Fig. 4e,f). Uncompacted eight-cell embryos showed brightly stained nuclei and prominent cytoplasmic granules with some staining in peripheral cytoplasm. Staining of peripheral cytoplasm disappears in the compacted eight-cell embryo, although the bright nuclear staining and cytoplasmic aggregates persist (Fig. $4 \mathrm{~g}, \mathrm{~h})$. Blastocysts show a reversal in the trend toward nuclear localization of DNA MTase, as bright cytoplasmic aggregates are prominent and staining of nuclei of both trophoblast cells and cells of the inner cell mass is very faint. DNA MTase is thus localized to the nucleus in significant amounts only around the eight-cell stage. The cytoplasmic localization of DNA MTase in embryos was unexpected, as DNA MTase is localized exclusively to the nuclei of somatic cells and of cultured embryonic stem (ES) cells (Leonhardt et al. 1992; L.L. Carlson, En Li, and T.H. Bestor, unpubl.). Furthermore, DNA MTase associates with sites of new DNA synthesis in nuclei of cultured cells (including wild-type ES cells) but has a diffuse nucleoplasmic distribution in non-S-phase cells. This association with replication foci is mediated by a targeting sequence near the amino terminus of DNA MTase (Leonhardt et al., in press). The nuclear staining seen in eight-cell embryos was always uniform (except for exclusion from nucleoli), as can be seen in Figure 4.

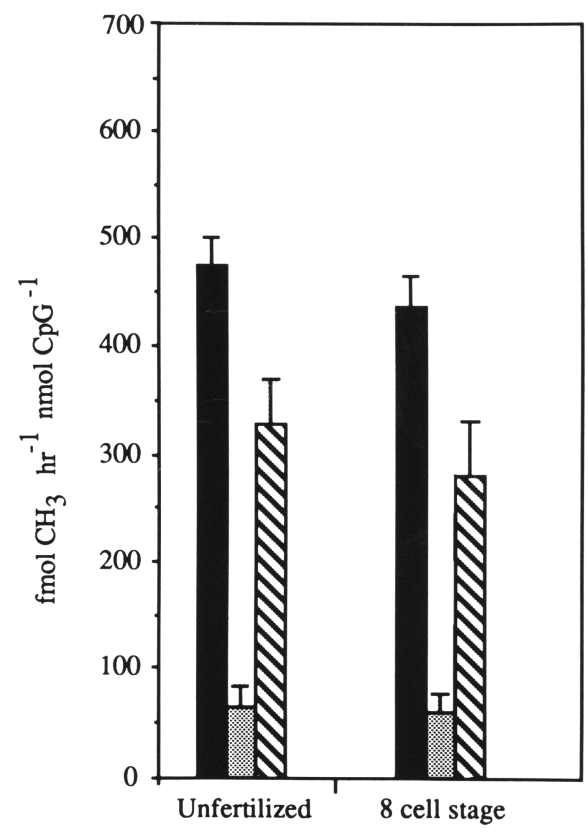

Figure 3. Comparison of the enzymatic activities of DNA MTase from unfertilized oocytes and eight-cell embryos. Both stages contain an activity that has a preference for hemimethylated $E$. coli DNA (hatched bar) and poly[d(I-C)]/poly[d(I-C)] (solid bar), over unmethylated E. coli DNA (stippled bar) as established for the somatic form of DNA MTase. As described elsewhere (Bestor 1992), DNA MTase responds to poly[d(I-C)]/ poly $[\mathrm{d}(\mathrm{I}-\mathrm{C})]$ as though it were hemimethylated. 

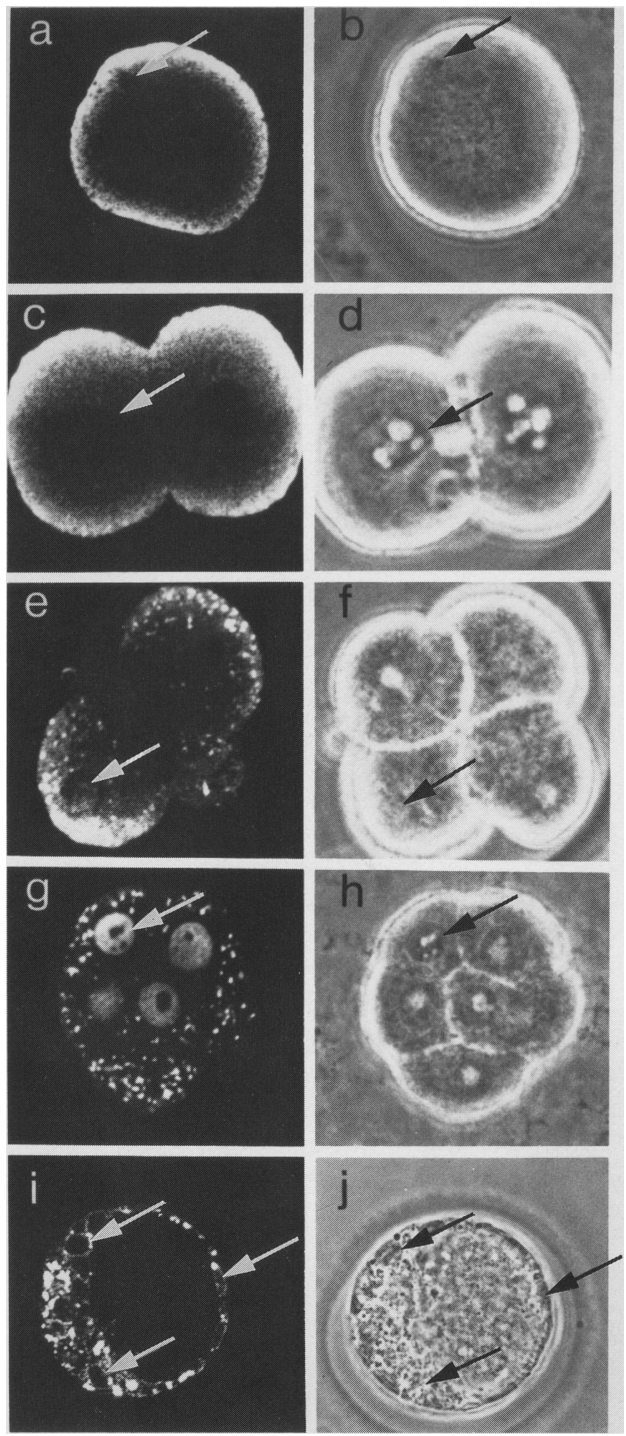

Figure 4. Localization of DNA MTase in preimplantation mouse embryos. Embryos at the one-cell $(a, b)$, two-cell $(c, d)$, four-cell $\langle e, f\rangle$, compacted eight-cell $\langle g, h|$, and blastocyst $\langle i, j|$ stages were stained with anti-pATH52 and examined in the confocal laser scanning microscope (left) and with phase contrast optics (right). Confocal micrographs are equatorial optical sections. Arrows indicate nuclei, except in $a$ and $b$, where a spindle is shown. Note that DNA MTase staining is in the peripheral cytoplasm near the plasma membrane in $a$ and $c$; in later stages, prominent cytoplasmic aggregates are conspicuous $|e, g, i|$. Some nuclear staining can be seen in the nucleus marked with the arrow in $e$; two blastomeres of this embryo are out of the plane of the optical section. Notice the intense nuclear staining and cytoplasmic granules in the eight-cell embryo shown in $g$ and the bright cytoplasmic staining and lack of nuclear staining in the blastocyst shown in $i$.

\section{Discussion}

Preimplantation development (especially between the eight-cell and blastocyst stages) is characterized by a decrease in total $\mathrm{m}^{5} \mathrm{C}$ content of nuclear DNA (Monk 1990|, which paradoxically occurs in the presence of very high levels of DNA MTase. The data presented here show that there are complex, developmentally regulated changes in the subcellular localization of DNA MTase during preimplantation development. It might be thought that spatial segregation of nuclear DNA and DNA MTase could account for demethylation in the presence of very high levels of DNA MTase, as confocal laser scanning microscopy revealed that most DNA MTase is cytoplasmic and associated with peripheral cytoplasm before the four-cell stage and with cytoplasmic granules thereafter. However, levels of nuclear DNA MTase are highest at the eight-cell stage, where the rate of demethylation of nuclear DNA is near a maximum (Monk 1990). It is also unlikely that DNA MTase is involved in the removal of methyl groups, as reversal of the transmethylation reaction as a means of removing methyl groups from $\mathrm{m}^{5} \mathrm{C}$ is unprecedented and highly improbable on chemical grounds. Because the enzyme in eight-cell embryos is fully active as a DNA MTase, it is unlikely that a modified form of DNA MTase has demethylating activity. We suggest that demethylation proceeds in the presence of high levels of DNA MTase through the action of unidentifed regulatory factors that modify the activity of DNA MTase in the nuclei of preimplantation embryos. This may involve exclusion from the multiprotein complexes in which DNA is replicated in mammalian nuclei. DNA MTase has been shown to concentrate in the vicinity of sites of DNA replication during $S$ phase in cultured cells; this is observed as a striking punctate staining pattern after staining with antibodies to DNA MTase (Leonhardt et al. 1992). In contrast, the nuclear staining observed in eight-cell embryos was invariably uniform. Demethylation could occur in the presence of high levels of DNA MTase if efficient methylation requires the close coordination of replication and methylation and if interactions between DNA MTase and replication foci are prevented.

The embryonic form of DNA MTase differs from the somatic form in that it has a slightly higher electrophoretic mobility on SDS-polyacrylamide gels. However, the somatic form of DNA MTase comigrates with the embryonic form when produced from a recombinant expression vector in COS cells or by in vitro transcriptiontranslation of a cloned cDNA. These data suggest that the embryonic form of DNA MTase is translated from alternative start sites or escapes post-translational modifications undergone by the somatic form. Many protein modifications decrease the rate of migration of proteins during SDS-polyacrylamide gel electrophoresis. The nature of the modification is not known, but it does not appear to affect the significant catalytic properties of the enzyme in vitro; the embryonic and somatic forms of DNA MTase have very similar specific activities, preferences for hemimethylated DNA, and de novo sequence specificities. Furthermore, no significant differences in enzymatic properties or rates of migration on SDS-polyacrylamide gels were identified by comparison of DNA MTase from unfertilized oocytes and eight-cell embryos, even though DNA MTase is localized almost exclusively in the cytoplasm of oocytes but is present at high levels 
in the nuclear compartment of eight-cell embryos. Although no evidence for additional species of DNA MTase was found in early embryos, their existence cannot be excluded by the data in hand.

It is likely that the different patterns of localization reported here are the result of intracellular movements of maternal DNA MTase because the large amounts of DNA MTase seen in preimplantation mouse embryos are present in oocytes at the germinal vesicle stage. It should also be noted that the large stores of DNA MTase observed in embryos should allow homozygous mutant embryos to complete the early stages of embryogenesis even if DNA MTase is essential for cell division. Dilution of maternal stores of DNA MTase is a likely explanation for the fact that targeted partial loss-of-function mutations in the DNA MTase gene allow homozygous embryos to develop to the 20 -somite stage but no further (Li et al. 1992).

The immunolocalization studies reported here suggest the existence of at least two types of factor that interact with DNA MTase in preimplantation embryos. The first is a factor or factors that sequester DNA MTase near the plasma membrane and in cytoplasmic aggregates. The second factor or collection of factors might act in the nuclei of eight-cell embryos to permit the loss of methyl groups from genomic $\mathrm{m}^{5} \mathrm{C}$ in the presence of high levels of DNA MTase; this could be the result of the presence of inhibitors or the absence of essential positive regulators. These factors may correspond to those in egg cytoplasm that modify the effects of genomic imprinting in preimplantation embryos (Latham and Solter 1991), or to the products of the Ssm-1 (Engler et al. 1991) or Imp-1 (Forejt and Gregorova 1992) genes, which have also been shown to affect genomic imprinting. Identification of the putative regulatory factors would be of great value to an understanding of the molecular mechanisms that establish sequence-specific methylation patterns during early mammalian development.

\section{Materials and methods}

\section{Embryos and oocytes}

Female CF1 mice (Charles River, Wilmington MA) were superovulated by standard methods (Hogan et al. 1986) and mated to BDF males. Hormonal stimulation and matings were timed to produce embryos of all the desired stages on a given day. Embryos and oocytes were flushed from oviducts or uteri with PBS containing $3 \mathrm{mg} / \mathrm{ml}$ of bovine senum albumin (BSA). All oocytes and embryos were washed by micropipette transfer with three changes of PBS to BSA.

\section{DNA MTase assays}

Oocytes or eight-cell embryos were lysed in $10 \mu \mathrm{l}$ of $20 \mathrm{~mm}$ Tris- $\mathrm{HCl}$ (pH 7.4), $5 \mathrm{~mm} \mathrm{Na}$ EDTA, 25\% glycerol, $0.1 \%$ Triton $\mathrm{X}-100$, and $400 \mathrm{~mm} \mathrm{NaCl}$. The lysate was added to $80 \mu \mathrm{l}$ of assay mixture containing $5 \mu \mathrm{Ci}$ of $\left[\right.$ methy $\left.1{ }^{3} \mathrm{H}\right] S$-adenosyl L-methionine (10-15 Ci/mmole; Amersham, Arlington Heights IL), 20 $\mathrm{mM}$ Tris- $\mathrm{HCl}$ (pH 7.4), $5 \mathrm{mM} \mathrm{Na}_{3}$ EDTA, 25\% glycerol, and either $2.5 \mu \mathrm{g}$ of poly[d(I-C)]/poly[d(I-C)] (Boehringer Mannheim, Indianapolis, IN), unmethylated $E$. coli DNA, or hemimethylated $E$. coli DNA. Unmethylated and hemimethylated $E$. coli
DNAs were synthesized as described (Bestor 1992). After $2 \mathrm{hr}$ at $37^{\circ} \mathrm{C}$, the samples were made $0.1 \mathrm{M}$ in $\mathrm{NaOH}$ and incubated at $55^{\circ} \mathrm{C}$. After $2 \mathrm{hr}$, Tris- $\mathrm{HCl}(\mathrm{pH} 7.4)$ was added to $0.5 \mathrm{M}$ and calf thymus carrier DNA to $400 \mu \mathrm{g} / \mathrm{ml}$. The samples were extracted with phenol/chloroform/isoamyl alcohol $(24: 24: 1)$ and precipitated with $10 \%$ trichloroacetic acid. The precipitates were collected by filtration on glass fiber filters and subjected to scintillation counting. Control samples lacked added DNA. De novo sequence specificity was evaluated as described previously (Bestor and Ingram 1985; Bestor 1987).

\section{In vitro transcription and translation}

The full-length DNA MTase cDNA was cloned into pBluescript $\mathrm{SK} \mid+$ ) (Stratagene, La Jolla, CA) and linearized by cleavage of a $K p n I$ site in the $3^{\prime}$ polylinker. RNA was produced from the DNA by transcription with $\mathrm{T} 3$ polymerase and purified by phenol extraction and ethanol precipitation. The RNA was dissolved in water, heated to $67^{\circ} \mathrm{C}$ for $10 \mathrm{~min}$, cooled on ice, and translated in a nuclease-treated rabbit reticulocyte in vitro translation reaction (Promega, Madison, WI) in the presence of $\mathrm{L}-\left[{ }^{35} \mathrm{~S}\right]$ methionine (Amersham). Control reactions lacked added RNA.

In vitro translation mixtures were immunoprecipitated before electrophoresis. Equal amounts of in vitro translation mixtures from control and experimental reactions were incubated with $10 \mu$ l of anti-pATH52, a polyclonal rabbit antibody against a DNA MTase-TrpE fusion protein that has been described previously (Bestor 1992; $\mathrm{Li}$ et al. 1992). After $30 \mathrm{~min}$ at $4^{\circ} \mathrm{C}$, one volume of a $50 \%$ (vol/vol) slurry of protein A-agarose (Boehringer-Mannheim/ was added and the incubation continued for $1 \mathrm{hr}$. The protein A-agarose beads were collected by centrifugation and washed three times with $50 \mathrm{~mm}$ Tris- $\mathrm{HCl}(\mathrm{pH} 7.5)$, $100 \mathrm{mM} \mathrm{NaCl}, 1 \mathrm{~mm}$ dithiothreitol, and $1 \mathrm{~mm}$ phenylmethylsulfonylfluoride. Bound protein was released by heating to $100^{\circ} \mathrm{C}$ for $2 \mathrm{~min}$ in $2 \% \mathrm{SDS}, 100 \mathrm{~mm}$ dithiothreitol.

\section{Gel electrophoresis and immunoblotting}

Immunoprecipitated in vitro translation products and lysates of normal MEL cells, mouse oocytes, and COS1 cells transfected with the mammalian eukaryotic DNA MTase expression vector pEMT (Czank et al. 1991) were denatured by heating to $100^{\circ} \mathrm{C}$ in the presence of $2 \%$ SDS and $100 \mathrm{~mm}$ dithiothreitol. Proteins were separated on SDS $-6 \%$ polyacrylamide gels and transferred to nitrocellulose sheets (BA85; Schleicher \& Schuell, Keene, $\mathrm{NH}$ ) or Problott PVDF membranes (Applied Biosystems, Foster City, CA) by electroblotting in a Hoefer semidry transfer apparatus (Hoefer Instruments, San Francisco, CA). Blots were probed with anti-pATH52, followed by alkaline phosphataseconjugated goat anti-rabbit IgG (Hyclone, Logan, UT) as described (Li et al. 1992). Bound antigen-antibody complexes were visualized either with the chromogenic substrates nitro blue tetrazolium and 5-bromo-4-chloro-3-indolyl phosphate (Harlow and Lane 1988) or with the sensitive chemiluminescent substrate AMPPD (Tropix Corp., Framingham, MA; Gillespie and Hudspeth 1991). Radiolabeled DNA MTase in the immunoprecipitate was detected by autoradiography of the blot, and accurate alignment of the immunoblot and autoradiogram was assured by placement of small dots of phosphorescent paint (The Nature Company, Boston, MA) on the PVDF membrane.

\section{Immunofluorescence}

Oocytes and embryos were flushed from oviducts or uteri in PBS with $3 \%$ goat serum, fixed in fresh $4 \%$ paraformaldehye on ice for 10 min, and treated with $0.2 \%$ Triton X-100 in PBS for 12 $\mathrm{min}$ and $50 \mathrm{~mm}$ glycine for $10 \mathrm{~min}$. The specimens were incu- 
bated in blocking buffer $[0.2 \%$ cold-water fish skin gelatin (Sigma), 5\% goat serum (GIBCO/BRL, Grand Island, NY) and $0.2 \%$ Tween 20 in PBS] for $30 \mathrm{~min}$, and incubated with a $1: 1000$ dilution of anti-pATH52 in blocking buffer for $1 \mathrm{hr}$. After washing three times with PBS and after a second incubation in blocking buffer for $30 \mathrm{~min}$, a rhodamine-labeled goat anti-rabbit antibody $(1: 300$ dilution; Tago, Burlingame, CA $)$ was applied for $30 \mathrm{~min}$. After three washes in PBS with $3 \%$ goat serum, the oocytes and embryos were transferred through a graded series of glycerol concentrations $2.5 \%, 5 \%, 10 \%, 20 \%$, and $50 \%$ in PBS) and mounted in $50 \mathrm{mg} / \mathrm{ml} n$-propyl gallate in glycerol. The specimens were examined with a Bio-Rad MRC500 confocal laser scanning instrument mounted on a Zeiss Axiophot microscope. A Zeiss $40 \times 1.3$ NA oil immersion objective was used, and micrographs were recorded by photography of images on a flat-screen video monitor. Preimmune serum gave only faint diffuse background staining and did not decorate the structures seen with immune serum. The specificity of the antiserum was further confirmed by immunoblot analysis, as shown in Figure 1, and by observation of a lack of significant staining in formaldehye-fixed mouse ES cells homozygous for a targeted disruption of the DNA MTase gene (Li et al. 1992, and data not shown).

\section{Acknowledgments}

We thank John D. Biggers, Susan Palmieri, and Jay Baltz for discussions and advice on mouse embryos, Richard Chaillet for comments on the manuscript, Heinrich Leonhardt for advice and help with COS cells, and Steve Borack for photography. This work was supported by National Institutes of Health (NIH) grant GM43565 and grant 5-716 from the March of Dimes Birth Defects Foundation (to T.H.B.), by NIH grant NS08807 (to L.L.C.), and by Reproductive Biology Training Grant HD07130 (to John D. Biggers).

The publication costs of this article were defrayed in part by payment of page charges. This article must therefore be hereby marked "advertisement" in accordance with 18 USC section 1734 solely to indicate this fact.

\section{References}

Bestor, T. 1987. Supercoiling-dependent sequence specificity of mammalian DNA methyltransferase. Nucleic Acids Res. 15: 3835-3843.

- 1992. Activation of mammalian DNA methyltransferase by cleavage of a $\mathrm{Zn}$-binding regulatory domain. $E M B O$ J. 11: 2611-2618

Bestor, T.H. and V.M. Ingram. 1983. Two DNA methyltransferases from murine erythroleukemia cells: Purification, sequence specificity, and mode of interaction with DNA. Proc. Natl. Acad. Sci. 80: 5559-5563.

Bestor, T.H. and V.M. Ingram. 1985. Growth-dependent expression of multiple species of DNA methyltransferase in murine erythroleukemia cells. Proc. Nat. Acad. Sci. 82: 2674 2678.

Bestor, T., A. Laudano, R. Mattaliano, and V. Ingram. 1988. Cloning and sequencing of a cDNA encoding DNA methyltransferase of mouse cells. The carboxyl-terminal domain of the mammalian enzymes is related to bacterial restriction methyltransferases. J. Mol. Biol. 203: 971-983.

Chaillet, J.R., T.F. Vogt, D.R. Beier, and P. Leder. 1991. Parentalspecific methylation of an imprinted transgene is established during gametogenesis and progressively changes during development. Cell 66: 77-83.

Czank, A., R. Hauselmann, A.W. Page, H. Leonhardt, T.H. Bestor, W. Schaffner, and M. Hergersberg. 1991. Expression in mammalian cells of a cloned gene encoding murine DNA methyltransferase. Gene 109: 259-263.

Engler, P., C. Haasch, C.A. Pinkert, L. Doglio, M. Glymour, R. Brinster, and U. Storb. 1991. A strain specific modifier on mouse chromosome 4 controls methylation of independent transgene loci. Cell 65: 939-947.

Forejt, J. and S. Gregorova. 1992. Genetic analysis of genomic imprinting: An Imprintor-1 gene controls inactivation of the paternal copy of the mouse Tme locus. Cell 70: 443-450.

Gillespie, P.G. and A.J. Hudspeth. 1991. Chemiluminescence detection of proteins from single cells. Proc. Nat. Acad. Sci. 88: 2563-2567.

Gruenbaum, Y., H. Cedar, and A. Razin. 1982. Substrate and sequence specificity of a eukaryotic DNA methylase. Nature 295: 620-622.

Harlow, E. and D. Lane. 1988. Antibodies: A laboratory manual. Cold Spring Harbor Laboratory, Cold Spring Harbor, New York.

Hogan, B., F. Costantini, and E. Lacy. 1986. Manipulating the mouse embryo. Cold Spring Harbor Laboratory, Cold Spring Harbor, New York.

Holliday, R. and J.E. Pugh. 1975. DNA modification mechanisms and gene activity during development. Science 187: 226-232.

Howlett, S.K. and W. Reik. 1991. Methylation levels of maternal and paternal genomes during preimplantation development. Development 113: 119-127.

Hubrich-Kuhner, K., H.J. Buhk, H. Wagner, H. Kroger, and D. Simon. 1989. Non-C-G recognition sequences of DNA cytosine-5-methyltransferase from rat liver. Biochem. Biophys. Res. Comm. 160: 1175-1182.

Jähner, D. and R. Jaenisch. 1984. DNA methylation in early mammalian development. In DNA methylation led. A. Razin, H. Cedar, and A. Riggs), pp. 189-219. Springer-Verlag, Berlin, Germany.

Latham, K.E. and D. Solter. 1991. Effect of egg composition on the developmental capacity of androgenetic mouse embryos. Development 113: 561-568.

Leonhardt, H., A.W. Page, H.U. Weier, and T.H. Bestor. 1992. A targetting sequence directs DNA methyltransferase to sites of DNA replication in mammalian nuclei. Cell 71: 865-874.

Li, E., T.H. Bestor, and R. Jaenisch. 1992. Targeted mutation of the DNA methyltransferase gene results in embryonic lethality. Cell 69: 915-926.

Monk, M. 1990. Changes in DNA methylation during mouse embryonic development in relation to X-chromosome activity and imprinting. Phil. Trans. R. Soc. Lond. Biol. Sci. 326: $179-187$.

Monk, M., M. Boubelik, and S. Lehnert. 1987. Temporal and regional changes in DNA methylation in the embryonic, extraembryonic, and germ cell lineages during mouse development. Development 99: 371-382

Monk, M., R.L. Adams, and A. Rinaldi. 1991. Decrease in DNA methylase activity during preimplantation development in the mouse. Development 112: 189-92.

Pedrali-Noy, G. and A. Weissbach. 1986. Mammalian DNA methyltransferases prefer poly $(\mathrm{dI}-\mathrm{dC})$ as substrate. J. Biol. Chem. 261: 7600-7602.

Razin, A. and H. Cedar. 1991. DNA methylation and gene expression. Microbiol. Rev. 55: 451-458.

Riggs, A.D. 1975. X inactivation, differentiation, and DNA methylation. Cytogenet. Cell Genet. 14: 9-25.

Takri, T., M. Ariel, M. Brandeis, R. Shemer, L. Urven, J. McCarrey, H. Cedar, and A. Razin. 1992. Developmental pattern of gene-specific DNA methylation in the mouse embryo and germ line. Genes \& Dev. 6: 705-714. 


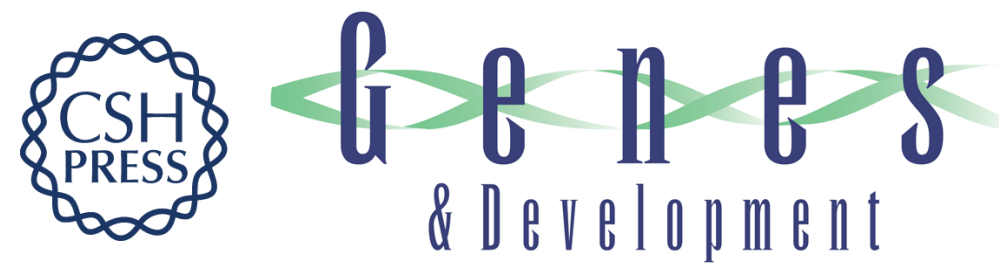

\section{Properties and localization of DNA methyltransferase in preimplantation mouse embryos: implications for genomic imprinting.}

L L Carlson, A W Page and T H Bestor

Genes Dev. 1992, 6:

Access the most recent version at doi:10.1101/gad.6.12b.2536

References This article cites 24 articles, 11 of which can be accessed free at:

http://genesdev.cshlp.org/content/6/12b/2536.full.html\#ref-list-1

License

Email Alerting Service

Receive free email alerts when new articles cite this article - sign up in the box at the top right corner of the article or click here.

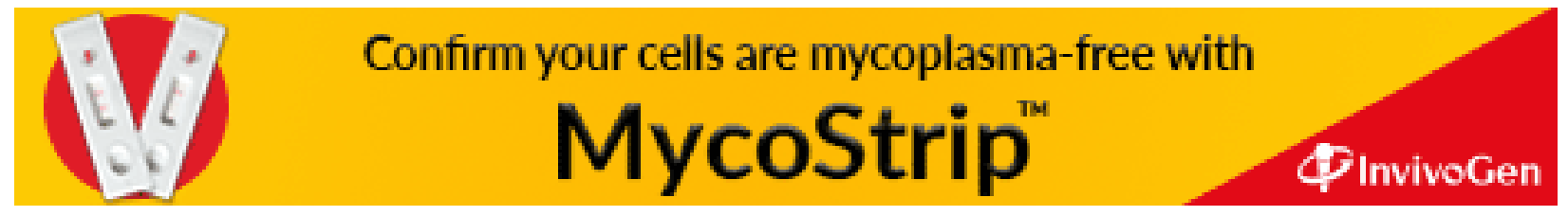

